\title{
Sustainable school food procurement: What factors do affect the introduction and the increase of organic food?
}

\author{
Rosalia Filippini ${ }^{\mathrm{a}}$, Ivan De Noni ${ }^{\mathrm{b}}$, Stefano Corsi ${ }^{\mathrm{a}, *}$, Roberto Spigarolo ${ }^{\mathrm{a}}$, Stefano Bocchi ${ }^{\mathrm{a}}$ \\ ${ }^{\text {a }}$ Department of Agricultural and Environmental Sciences - Production, Landscape, Agroenergy, University of Milan, Via Celoria, 2, Milan, Italy \\ b Department of Economics, Management and Quantitative Method, University of Milan, Via Conservatorio 7, Milan, Italy
}

\section{A R T I C L E I N F O}

\section{Keywords:}

GPP

Public school food procurement

Food policy

Zero-inflated negative binomial modelling

Italy

\begin{abstract}
A B S T R A C T
Public School Food Procurements (PSFPs) are recognized as drivers of food and nutrition security. In the last decade, researchers and institutions have focused on designing sustainable school food procurements that include organic food. This study examines the public food procurement system in 524 of the 1554 municipalities of Lombardy in Northern Italy. A Zero-Inflated Negative Binomial model is used to explore the factors affecting the initial adoption and the increase of organic food in PSFP at the regional level. Four sets of factors are investigated, including territorial indicators, market constraints, PSFP's management and governance and concern for local and certified origin products. The results show that the initial introduction of organic food correlates with higher population density and bigger farms in the area and strongly depends on pressure from municipal administrations and canteen committee for environmental sustainability and youth health. However, the introduction of organic food often must be driven by the initiative of catering service management and must take into account municipal policies to support the local production and certified origin products. Conversely, the adoption intensity increases when PSFP is managed by private companies and stakeholder pressure is strong, although the adoption intensity can be adversely affected by higher perceived costs of organic products when compared to conventional products. This analysis thus confirms the importance of the participation of local stakeholders in designing more sustainable PSFP. The analysis also provides local stakeholders with a systematic dataset at the regional scale regarding the factors that drive sustainable choices in PSFP. The analysis thus supports institutions and policy-makers in coordinating the alignment between food demand and supply in order to better address the sustainability.
\end{abstract}

\section{Introduction}

Public procurement is a highly discussed topic at the municipal, national and European levels. Moreover, public procurement represented $19 \%$ of the GDP at the EU-wide level in 2014 (European Commission, 2015) and increased by $6.9 \%$ in 2015 (European Commission, 2016a). In 2004, the Green Public Procurement (GPP), which was part of the EU procurement policies, was introduced as an instrument to encourage public authorities to use their "purchasing power" to ensure sustainable consumption and production patterns (European Union, 2016b).

The monitoring of GPP adoption across European countries has revealed that even if GPP uptake is increasing, in 2010 only $26 \%$ of the total number of contracts were considered "green", which does not meet the European Commission's target of 50\% made in 2004 (Renda et al., 2012). Moreover, the uptake of GPP varies among product groups: while only the "Transport" product group meets the 50\% target set at the EU level, the "Food Procurement and Catering Services" remain below $20 \%$. Despite the efforts of public authorities in green procurement, a lot must be done, and the GPP criteria for product groups is now under revision to improve public authority engagement (Boyano et al., 2017).

Concerning the large demand for food and the critical mass involved, few food chains can influence the way food is produced, processed and distributed and thus deeply reduce the environmental impacts of food supply chains. The purpose of GPP is to reinforce the role of public procurement in addressing sustainability issues (Goggins and Rau, 2016; European Commission, 2016). GPP supports the overcoming of traditional cost-effectiveness criteria driving public procurement to foster better social, health and environmental conditions (De Schutter, 2014; Cerutti et al., 2016).

A critical role in orienting the sustainability of GPP is specifically

\footnotetext{
* Corresponding author.

E-mail addresses: rosalia.filippini@unimi.it (R. Filippini), ivan.denoni@unimi.it (I. De Noni), stefano.corsi@unimi.it (S. Corsi), roberto.spigarolo@unimi.it (R. Spigarolo), stefano.bocchi@unimi.it (S. Bocchi).
} 
played by the Public School Food Procurement (PSFP). In fact, in terms of volume and value of the total meals served, the "Education" sector accounts for $31.4 \%$ of the total meals served, and it is second only to the "Health" sector, which accounts for $42.7 \%$ (Boyano et al., 2017). Organic food is among the criteria to reach GPP goals (European Commission, 2008) and the use of organic labels may also serve to increase the awareness of consumers regarding the need to change direction toward sustainability (European Commission, 2016b). According to the literature, the PSFP can be seen as a "litmus test of the state's commitment to sustainable development" (Morgan, 2008, p. 1237).

The adoption of GPP is delegated to the Member States that adopt National Action Plans to green their public procurement. In Italy, the GPP National Action Plan was initially released in 2008 (Italian Ministry of Environment and the Protection of Natural Resources, 2008). It has been followed by the National Guidelines for School Catering (Italian Ministry of Health, 2010) and the definition of Minimum Environmental Criteria (CAM) (Italian Ministry of Environment and the Protection of Natural Resources, 2011a). In the CAM, the inclusion of organic food in public procurement is specifically requested in order to reduce the impact of public meals on the environment, during the production phase (Italian Ministry of Environment and the Protection of Natural Resources, 2011b). Beyond organic food, in the application of the EU GPP, the CAM emphasize the need for food quality, freshness and healthiness as well as regional food specificities. The care for traditions and individual well-being, which are typical Italian values leads people to retain control of food and to have a higher disposition to the introduction of organic and quality products in their eating behavior, influencing also PSFP purchasing power (Morgan and Sonnino, 2008; Grossi et al., 2011). In general, Italy has been considered one of the most committed countries in Europe regarding the provision of organic and quality food in PSFP, and local institutions are actively promoting the inclusion of organic and local products in schools' canteens (Nölting, 2009; Maietta and Gorgitano, 2016). Moreover, by claiming actions of information and awareness, Italian regulations recognize the PSFP as a unique arena for "social learning" and thus an opportunity for public authorities to encourage users, including teachers, workers, pupils and their families, to adopt more sustainable ways of consumption in their everyday lives (Wahlen et al., 2012), to "empower consumers by building their capacity to eat healthily" (Morgan and Sonnino, 2007, p.1). The school meals are also recognized as an opportunity to valorise and conserve local Italian traditions, and institutions are requested to consider the preferences of local consumers (Maietta and Gorgitano, 2016; Morgan and Sonnino, 2007). The GPP was introduced while in Italy the "school food revolution" was already operating (Morgan and Sonnino, 2008), which reflects the long-term attention of PSFP on quality food (Ecosistemi, 2012). According to Morgan and Sonnino (2008: 97), "the Italian system of public food procurement is considered a product, rather than a cause, of a deeply embedded culture that connects school meals (and food in general) to local identity".

However, despite this national tendency, data suggest that the Italian procurement of organic food is still specifically concentrated in the North ( $71 \%$ of total organic food consumed in Italy) rather than in the Centre or in the South (18\% and $11 \%$, respectively) of the country. Across Italian regions, Lombardy is the most important in terms of business volume, number of food procurement tenders (1172 tenders for almost EUR 2 billion) (Chamber of Commerce, 2014), number of school canteens provided with organic products (241) and meals provided $(298,000)$ in 2016 (Bio Bank, 2017). This framework makes the analysis of organic food-oriented PSFP in Lombardy a fascinating case study.
The aim of this study is to analyze the factors that affect the adoption of organic food in PSFP at the regional scale; specifically, we explore the factors that explain the introduction and the adoption intensity of organic products in the PSFP at the municipal level. A ZeroInflated Negative Binomial model is implemented to measure both the likelihood of introducing organic products and the number of food typologies in which the organic food is introduced. The paper is structured as follows. The first section defines the literature background on sustainable PSFP and the role of organic food in this process. The second section focuses on defining the methodological approach. Sample, data collection, variables and modelling specifications are described. The last two sections respectively report the results of analysis and make suggestions for procurement policies.

\section{Literature review}

\subsection{Sustainable public school food procurement and the adoption of organic food}

The Minimum Environmental Criteria (CAM) not only aim to reduce the environmental impact of the public expenditure but also include criteria of social inclusion and economic sustainability. Two kinds of criteria are defined: the "basic criteria" and the "rewarding criteria". The basic criteria define the "green" procurement (Italian Ministry of Environment and the Protection of Natural Resources, 2011a) by establishing the percentages of the total weight of the food provided that should stem from organic production as certified by the EU, and from integrated system production, PGI (Protected Geographical Indications), PDO (Protected Designation of Origin), TSGs (Traditional Specialties Guaranteed) for the different product categories.

To consider the environmental, economic and social sustainability aspects and provide the market with an appropriate signal (Italian Ministry of Environment and the Protection of Natural Resources, 2011a), the "rewarding" criteria were added to define "the most economically advantageous tender" option by assigning more value to offers that consider (in order of importance) a: (i) higher percentage share of quality food beyond the basic criteria; (ii) products with lower carbon footprints; (iii) actions of unsupplied food recovery to allocate it to non-profit organizations of social utility; (iv) the use of Fair Trade for exotic products.

In Italy, the number of school canteens with organic food has increased rapidly, going from 69 school canteens with organic food in 1996 to 1288 in 2016 (BioBank, 2017). While 23\% of school canteens attain at least $70 \%$ of their primary products from organic production (BioBank, 2017), only $4.8 \%$ of them are completely organic (Maietta and Gorgitano, 2016). In the CAM, the amount of products to be included in public procurement are measured in terms of volume and not in variety of products. Moreover, in 2012, the percentage of contracting stations that included organic food was $96 \%$, but only $34 \%$ applied the minimum percentage requested by CAM's basic criteria. In other word, the provision of organic food was still considered among the rewarding criteria, as several constraints appeared difficult to overcome and CAM appeared too strict (Ecosistemi, 2012).

In the CAM, the adoption of organic food and products with integrated pest control significantly contributes to the reduction of environmental impacts. The adoption of organic food is not only among the basic criteria to have a green procurement, but it is also the most requested one (Italian Ministry of Environment and the Protection of Natural Resources, 2011b). In the GPP, the procurement of organic food is among the "core GPP criteria" to avoid eutrophication, acidification and toxic impacts on human health and the environment due to 
pesticides and fertilizer residues present in water, air, soil and food (European Commission, 2008), and the procurement of organic food is considered a way to ensure and foster the sustainability of PSFP (De Schutter, 2014). According to research, the environmental benefits of organic food rely on the lower impact of the production phase, during which the core of organic production is based on the crop rotation, the crop diversity and the use of manure, all of which improves the fertility of soil and the biodiversity (Brantsæter et al., 2017). Smith et al. (2016) have also observed that European municipalities consider the inclusion of organic food as the first step in the adoption of more sustainable food procurement. Empirical evidence has indicated that the PSFP conversion to organic food has led to several other outcomes: the introduction of organic food positively influences the commitment of institutions to healthy food and balanced diets through the reduction of meat and the inclusion of more vegetables dishes in order to absorb the price premium of organic certifications; it is an opportunity to redesign the procurement processes to improve its efficiency; and all the actors involved in the PSFP have the opportunity to increase awareness of the importance of healthy and sustainable diets (Mikkelsen and Sylvest, 2012; Nölting, 2009).

\subsection{The factors affecting the introduction of organic food in PSFP}

The introduction of PGI, PDO and TSG among the basic criteria in the CAM seeks to valorise the quality foods, thus protecting the regional peculiarities - both the regional characteristics of food production and the local savoir faire of traditional products - and the local economy from possible unfair competition (Italian Ministry of Environment and the Protection of Natural Resources, 2011b). In this way, the capacity of PSFP to create a market is valorised by creating a huge demand for quality food and addressing the food supply (New et al., 2002; Sonnino, 2009). Such certifications represent a quality's for consumers, since production specifications are followed for such products (Italian Ministry of Environment and the Protection of Natural Resources, 2011b). The valorisation of the local economy is also done through the demand of fresh, organic and seasonal products (Italian Ministry of Environment and the Protection of Natural Resources, 2011b), thus combining the attention to pupils' nutrition with economic sustainability (Maietta and Gorgitano, 2016), supporting local food supply chains and involving farmers, farmers associations, intermediates, agribusiness, processors, etc. (Izumi et al., 2010). The territorial alignment between the organic supply and organic demand of PSFP is important because research has shown that when combined with local procurement, organic procurement is less energy demanding (Caputo et al., 2017); moreover, such territorial alignment may provide a positive impact on the economy of the local farming system: PSFP may represent a strong market to drive the local organic production (Wahlen et al., 2012). Several scholars have deal with the need for a re-localisation of the PSFP food chain (Risku-Norja and Loes, 2016; Goggins and Rau, 2016). Nevertheless, the definition of what is "local" is a matter of debate between practitioners, scholars and policy-makers (Kneafsey et al., 2013; Brunori et al., 2016). According to Brunori et al. (2016) the definition of "localness" and its benefits depend on different elements characterising the food chain, as the physical distances, the governance, the product identity, the size of operation. For this reason, such definition must be adapted to the specific conditions of the supply and demand in the different case studies. The definition of "localness" in the PSFP food chain, must thus consider that where the PSFP's demand size can be different according to the number of meals to be provided (Goggins and Rau, 2016).

Literature has shown some weaknesses in the local organic food procurement. First, several concerns regard the availability of organic production, due to season and logistics (Sonnino, 2009; Risku-Norja and Løes, 2016), and its potential unstable deliveries (Mikkelsen and Sylvest, 2012). According to literature, this is especially the case for the demand stemming from urban areas. Despite studies on consumers' behavior have pointed out that the purchase of organic food is more prominent among urban consumers (Agovino et al., 2017; Radman, 2005; Torjusen et al., 2004), qualitative studies on public procurement have reported the difficulty of including local organic food in urban school catering. Though deeper consideration is needed, according to authors, the large volumes demanded by the urban catering system require the catering companies to rely on a food platform that does not have a local base (Sonnino, 2009). The local supply often does not meet the demand (Risku-Norja and Løes, 2016), especially when organic food is locally produced only by small farms and enterprises (Lehtinen, 2012). There is thus a possible trade-off between the environmental benefits of organic food production and the environmental deficits of long food chains (Smith et al., 2016). Conversely, to respond to urban public food procurement, conventional products have a good qualitative standard that complies with basic food safety and hygienic requirements, and they are more suitable in terms of the volume and organization of the supply (Sonnino, 2009; Lehtinen, 2012).

Second, the cost of organic food is considered one of the most important drawbacks of organic food purchasing (Lehtinen, 2012; Mikkelsen and Sylvest, 2012; Italian Ministry of Environment and the Protection of Natural Resources, 2011b; Risku-Norja and Løes, 2016). For example, in their consumers' preference study, Gracia and de Magistris (2008) reported that economic factors, such as the organic food price and the household income, are more significant than sociodemographic factors such as age, education and gender. In the case of public procurement, the financial pressure for economic efficiency has exacerbated the preference for low-cost meals to the detriment of food quality (Lehtinen, 2012; Smith et al., 2016). Nevertheless, the introduction of "the most economically advantageous tender" criteria in the EU Regulation and in Italy, should have been allowed to overpass the strict cost-effectiveness criteria and consider social and environmental externalities as "economically advantageous" options to generate more possibilities for organic food. To reduce the impact of increasing costs, the CAM even advise municipalities to start the process by including organic production which is available locally and has a lower price gap compared with conventional products; making collective purchases; purchasing organic products directly from producers, thus saving on distribution costs. In literature, other cost mitigation actions include the menu reformulation, for example by reducing the more expensive meat dishes in favour of the cheaper vegetables ones, or by preferring seasonal products (Mikkelsen et al., 2012; Caputo et al., 2017; Nuutila and Kurppa, 2017). Nevertheless, PSFPs are only gradually including local and organic products in their schools' canteens (Galli and Brunori, 2012; Bocchi et al., 2009). For example, even if public authorities in the municipality of Rome "did not consider 'quality' and 'price' as irreconcilable goals" (Morgan and Sonnino, 2008, p. 77), a compromise between quality food and low price is still necessary (Sonnino, 2009). Such compromise is therefore the result of the consolidation of different PSFP stakeholders' beliefs and strategies.

In the literature, credence attributes such as health benefits, environmental sustainability and local origin of the food are considered significant factors in driving consumer choices toward organic food (Gracia and de Magistris, 2008). While the environmental benefits have been mostly verified, the impact on human health is not clear and require further investigation (Brantsæter et al., 2017). To our knowledge, quantitative analysis on the credence attributes that drive the choice of 
organic food in public procurement are missing. Qualitative studies have pointed out the importance of the commitment and the motivations of the different actors in public food procurement (Mikkelsen and Sylvest, 2012; Wahlen et al., 2012; Galli et al., 2014; Grandia et al., 2015). While in consumers behavior studies the focus is mainly on the individual consumers' willingness to buy organic food, considering their characters and their credence (i.e. Gracia and de Magistris, 2008), in public procurement a more complex social interaction drives the choice to buy organic food (Nölting, 2009; Sonnino, 2009; Galli et al., 2014; Maietta and Gorgitano, 2016). The supply of organic and quality food is the result of three dimensions: the users of the service, which are the students and their families; the administrators of the service, which are the local municipalities; and the providers of the service, such as the catering company that acts according to the market (Galli et al., 2014; Maietta and Gorgitano, 2016).

Family and civil society play a key role in addressing specific requests to the local public authorities. At the same time, the exchange between administrators and users is considered an important step to foster the inclusion of organic food (Mikkelsen and Sylvest, 2012; Clelland et al., 2013), considering the possible initial doubts of the families (Morgan and Sonnino, 2008). In Italy, families participate by paying an amount of money ${ }^{1}$ for the meals and by participating in the "Canteen Committee" (Galli et al., 2014; Morgan and Sonnino, 2008). The Canteen Committee also includes a representative from the local hygienic institution and experts of food nutrition out of the belief that sharing "the public responsibility with the community" is a solution to foster sustainable PSFP (Galli et al., 2014). According to Galli et al. (2014), this also represents a reduction of transaction costs in terms of the communication flow in the process of innovation. Nevertheless, it may also represent a source of conflict between parents and other public procurement's stakeholders (Galli et al., 2014).

The public purchasing power relies on local public bodies that have better knowledge of the territorial context and can better drive the public purchasing power for the benefit of the community (Løes and Nölting, 2011). In Italy, the National Guidelines for School Catering provides local municipalities with advice and guidelines to pursue the inclusion of organic food in PSFP (Italian Ministry of Health, 2010). Nevertheless, several internal constraints may still undermine this process: in local public institutions, the different dimensions of public procurement are in charge of different bodies that are not accustomed to working together (Morgan, 2008); the presence of formal procedures and routines have exasperated the bureaucratization (New et al., 2002); the lack of skills in people involved in the GPP is related to a lack of information about the different sustainable options; the perception of higher costs is changing; and the legal framework is uncertain. These factors may hamper the design of an innovative solution for sustainable PFSP (Grandia et al., 2015). In this framework, to overcome the intrinsic inertia to move toward a more sustainable food procurement system (Morgan, 2008), studies have revealed that the commitment of public officers at the municipal level is a key element in facilitating the change and overcoming the constraints (Mikkelsen and Sylvest, 2012; Testa et al., 2016). According to Grandia et al. (2015), such commitment should be especially based on the public officer's understanding of the social benefits of a more sustainable and green procurement.

Finally, the catering companies play an important role in the supply of meals in public schools (Rimmington et al., 2006; Neto et al., 2016). In Europe, $78 \%$ of the meals served in 2013 for the education sector were provided by contracted catering companies (Neto et al., 2016a). In Italy, $74 \%$ of the municipalities rely only on contractors to organize the supply in PFSP, while only $15 \%$ directly manage the PFSP, and the remaining 59\% adopt a mixed solution (Galli and Brunori, 2012).

\footnotetext{
${ }^{1}$ According to ISTAT (2012), among the Italian students under 14 years old, 53.4\% of them have lunch at school: $64.4 \%$ attends nursery and pre-school (0-6), 26.7\% are in primary school (6-10), and $6.1 \%$ secondary school (10-13).
}

Contractors are responsible for organizing the supply, distributing and transporting the food and preparing and administering the meal. Thus, they are responsible for practically designing the sustainability of the food chain and integrating the sustainability's requirements of local public tenders, while working in a highly competitive market. Contractors know that they are important actors for shifting toward more environmentally friendly food consumption (Bergström et al., 2005) and they participate in the "Canteen Committees" (Sonnino, 2009; Galli et al., 2014). For caterers, the introduction of CAM involves increasing the costs of the food provision as well as the costs for logistics and transportation (Italian Ministry of Environment and the Protection of Natural Resources, 2011b). The literature has shown that when facing costs increases, private companies may adopt an opportunistic business strategy to limit the provision's costs but undermine the quality of their procurement (Maietta and Gorgitano, 2016). According to the literature, in order to prevent such opportunism, the good reputation of past performances may be a source of pressure to increase the quality of their provision, thus facilitating their participation in future tenders, especially for small companies (Maietta and Gorgitano, 2016). In the "school food revolution", the position of catering companies is thus fundamental and peculiar, as the catering companies must ensure the volume and quality of the demanded food and maintain competitive prices (Morgan and Sonnino, 2008).

Following the literature, in this study the conceptual model of the adoption of organic food in PFSP is defined according to four groups of factors. First, the adoption of organic food is connected to territorial factors, which by the one side refer to the features of the local agricultural systems, concerning farm structure and orientation toward organic products, and by the other side refer to other territorial elements, such as the population density (Torjusen et al., 2004; Lehtinen, 2012). In the second group the introduction of organic food is affected by market constrains, such as its availability and the costs for organic procurement in comparison to the conventional one (Lehtinen, 2012; Mikkelsen and Sylvest, 2012; Risku-Norja and Loes, 2016). The third cluster relates the inclusion of organic food in public procurement to the actors involved in the PFSP: public bodies, catering companies and Canteen Committees (Galli et al., 2014). Their presence and their pressure in fostering the adoption of organic food, define the management and the governance of the PSFP (Grandia et al., 2015). Finally, in the fourth group the inclusion of organic food is connected to the adoption of local and certified food following the CAM requirements (Italian Ministry of Environment and the Protection of Natural resources, 2011a).

\section{Methodology}

\subsection{Sample and data gathering}

This study examined the PSFP of Lombardy from 2011 to 2013. The project, coordinated by the University of Milan, involved ANCI Lombardia (National Association of Municipalities in Lombardy), AIAB (Italian Association for Organic Agriculture) and ProBER (Association of Organic and Biodynamic Producers from Emilia Romagna). A questionnaire containing both qualitative and quantitative items was defined by a working group, which included academic researchers and PSFP stakeholders, such as municipal and regional officials, representatives of catering companies and local producers of conventional and organic products. Further improvements were suggested by testing the survey on a focus group of matter experts and stakeholders. The self-administrated questionnaire with mostly semi-open questions was finally submitted to the public functionaries of 1546 municipalities in Lombardy. It was jointly run by Ancitel Lombardia, which is the service company of ANCI that supports local authorities in the management of all the processes of innovation. When required, Ancitel also supported municipal officials in order to facilitate the understanding, avoid any misunderstanding and foster the compilation process. Even 
Table 1

Variables definition and descriptive statistics.

\begin{tabular}{|c|c|c|c|}
\hline Variable & Description & Type & Value \\
\hline BIO.ADP & Number of organic product types which are introduced in the PSFP & Integer & $\operatorname{Min}=0$, Mean $=8.51$, St.Dev $=9.39$, Max $=39$ \\
\hline \multicolumn{4}{|c|}{ Territorial variables } \\
\hline POP.DEN & Population density (logarithm of inhabitants per km2) & Numeric & $\operatorname{Min}=2.98$, Mean $=6.15$, St.Dev $=1.15$, Max $=8.93$ \\
\hline SZE.PSS & Size of local public school system (number of monthly meals) & Numeric & Min $=0$, Mean $=10607$, St.Dev $=49945.81$, Max $=8762$ \\
\hline BIO.CAP & Utilized agricultural area devoted to organic production (hectares) & Numeric & $\operatorname{Min}=0$, Mean $=12.49$, St.Dev $=70.27$, Max $=1251.9$ \\
\hline FRM.DEN & Number of agricultural farms on the territory & Numeric & $\operatorname{Min}=1$, Mean $=42.86$, St.Dev $=52.31, \operatorname{Max}=378$ \\
\hline SZE.FRM & Utilized agricultural area per local farm (hectares per farm) & Numeric & $\begin{array}{l}\text { Min }=0.38, \text { Mean }=18.46, \text { St.Dev }=17.78 \\
\operatorname{Max}=125.79\end{array}$ \\
\hline \multicolumn{4}{|c|}{ Market constraints } \\
\hline MKT.SPP & Shortage of organic food in the local market $(1=$ yes, $0=$ no $)$ & Binary & Freq. 1 (92), 0 (432) \\
\hline MKT.CST & Cost of organic food higher than conventional $(1=$ yes, $0=$ no $)$ & Binary & Freq. 1 (255), 0 (269) \\
\hline \multicolumn{4}{|c|}{ PSFP Management and governance } \\
\hline MNG.PRV & PSFP is managed by private company $(1=$ yes, $0=$ no $)$ & Binary & Freq. 1 (475), 0 (49) \\
\hline CTR.BRD & Presence of a Canteen Committee $(1=$ yes, $0=$ no $)$ & Binary & Freq. 1 (430), 0 (94) \\
\hline MNG.STR & Organic food adoption is driven by catering service management $(1=$ yes, $0=$ no $)$ & Binary & Freq. 1 (218), 0 (306) \\
\hline CTR.PRS & $\begin{array}{l}\text { Organic food adoption due to pressure by Canteen Committee and resident families } \\
(1=\text { yes, } 0=\text { no })\end{array}$ & Binary & Freq. 1 (49), 0 (475) \\
\hline ADM.PRS1 & $\begin{array}{l}\text { Organic food adoption due to pressure by administration for environmental safety }(1=\text { yes, } \\
0=\text { no })\end{array}$ & Binary & Freq. 1 (178), 0 (346) \\
\hline ADM.PRS2 & Organic food adoption due to pressure by administration for child health $(1=$ yes, $0=$ no $)$ & Binary & Freq. 1 (207), 0 (317) \\
\hline \multicolumn{4}{|c|}{ Concern for local and certified origin production } \\
\hline LOC.RSP & Attention to local/regional production - supply basin perspective $(1=$ yes, $0=$ no $)$ & Binary & Freq. 1 (251), 0 (273) \\
\hline QLT.RSP & Attention to PDO/PGI quality of products $(1=$ yes, $0=$ no $)$ & Binary & Freq. 1 (311), 0 (213) \\
\hline
\end{tabular}

though the response rate was $39.1 \%$ (of municipalities) representing $71.2 \%$ of the regional population $(9,826,141$ inhabitants), the final sample involved 524 municipalities because of incomplete questionnaires. It was a significant sample considering that some municipalities that did not respond were missing from the public school system and that similar studies typically adopt a sample that represents at least $5 \%$ of the total population. Finally, each municipality is then associated with demographic and environmental attributes provided by ISTAT (Italian National Institute of Statistics) such as the municipal area, the resident population and the province to which the municipality belongs.

\subsection{Variables}

\subsubsection{Dependent variable}

In the analysis, the adoption intensity of organic products (BIO.ADP) is the dependent variable. It is calculated by considering the number of different organic products that have been introduced in the PSFP of each municipality. In the survey compilation, the municipal officials were required to specify for each of the 48 product types (see Appendix A) whether organic products were supplied. Therefore, a count variable was operationalized by summarizing the number of food typologies introducing organic products in the PSFP of each municipality. Zero corresponds to no adoption of organic products. ${ }^{2}$ The higher the value of the index, the more diversified the adoption of organic food by school catering across the different food typologies. There are some limitations of this measure. First, this measure does not consider the absolute quantity of consumed organic food within the local public school system but only the food typologies in order to limit the size effect. Second, the procurement of conventional and organic food may coexist within the same product type.

\subsubsection{Explanatory variables}

In the attempt to understand the factors that affect the adoption of organic food in PSFP, a number of explanatory variables have been

\footnotetext{
${ }^{2}$ Even if the contractual obligation to introduce organic food in PSFP was established by CAM in 2011, the presence of zero in the dataset is justified because the criteria were not effectively applied in the short run, and a number of tenders had been activated before adoption of the criteria.
}

identified in the questionnaires, including territorial features, market constraints, PSFP's management and governance and concern for local and certified origin production (Table 1).

The territorial features were added to the information of the survey in order to understand if the context in which PSFP takes place may influence the inclusion of organic food, as done in previous studies (Maietta and Gorgitano, 2016) and according to studies on the territorial factors driving consumer behavior (Torjusen et al., 2004): they involve the density of the population and farms, the average farm size, the local production capacity and the size of the public school's canteen system. Specifically, the logarithmic transformation of number of residents per square kilometre (POP.DEN) is adopted as a proxy of municipality size and urbanization level (Gracia and de Magistris, 2008; Torjusen et al., 2004). The size of the public school system within the municipality (SZE.PSS) is based on the monthly number of meals provided by the PSFP. The farm density (FRM.DEN) is operationalized as the number of agricultural farms in the territory. The average size of agricultural farms (SZE.FRM) is computed as the utilized agricultural area per local farm. The utilized agricultural area devoted to organic cultivation measures the potential capacity of a municipality to produce organic food (BIO.CAP). These variables provide information about the local production system (Norja and Loes, 2016).

The market factors refer to the constraints related to the availability and cost of adopting organic food, as in previous literature. Because organic production is less widespread than conventional production, the introduction of organic food in PSFP may be limited because of the shortage of supply on the market (MKT.SPP) (Risku-Norja and Løes, 2016). Similarly, because organic agriculture typically requires higher production costs, the potential higher price of organic foods (MKT.CST) may reduce the management's will to introduce organic foods in public school procurement (Lehtinen, 2012; Mikkelsen and Sylvest, 2012; Italian Ministry of Environment and the Protection of Natural Resources, 2011b; Risku-Norja and Løes, 2016).

Considering the complex social interaction that drives organic procurement in public schools (Galli et al., 2014; Maietta and Gorgitano, 2016; Nölting, 2009; Sonnino, 2009; Grandia et al., 2015; Mikkelsen and Sylvest, 2012), the management and the governance of PSFP are two critically interconnected aspects that can impact both the choice to introduce organic food and the adoption level. First, a binary variable is introduced to assess the role of private versus public management (MNG.PRV). It is specified to be 1 if the PSFP is subcontracted 
Table 2

Correlation matrix.

\begin{tabular}{|c|c|c|c|c|c|c|c|c|c|c|c|c|c|c|c|c|}
\hline Variables & 1 & 2 & 3 & 4 & 5 & 6 & 7 & 8 & 9 & 10 & 11 & 12 & 13 & 14 & 15 & 16 \\
\hline 1. BIO.ADP & 1.00 & & & & & & & & & & & & & & & \\
\hline 2. POP.DEN & 0.39 & 1.00 & & & & & & & & & & & & & & \\
\hline 3. FRM.DEN & -0.08 & -0.31 & 1.00 & & & & & & & & & & & & & \\
\hline 4. SZE.FRM & -0.08 & -0.27 & -0.06 & 1.00 & & & & & & & & & & & & \\
\hline 5. BIO.CAP & -0.08 & -0.11 & 0.13 & 0.21 & 1.00 & & & & & & & & & & & \\
\hline 6. SZE.PSS & 0.06 & 0.24 & 0.06 & 0.03 & 0.06 & 1.00 & & & & & & & & & & \\
\hline 7. MKT.SPP & 0.05 & 0.19 & 0.02 & -0.02 & 0.04 & 0.39 & 1.00 & & & & & & & & & \\
\hline 8. MKT.CST & -0.12 & 0.04 & 0.05 & -0.12 & 0.16 & 0.08 & 0.31 & 1.00 & & & & & & & & \\
\hline 9. MNG.PRV & 0.53 & 0.29 & -0.14 & -0.02 & -0.03 & -0.15 & -0.08 & -0.18 & 1.00 & & & & & & & \\
\hline 10. MNG.STR & 0.42 & 0.35 & -0.13 & -0.12 & 0.02 & 0.01 & 0.07 & -0.11 & 0.39 & 1.00 & & & & & & \\
\hline 11. CTR.BRD & 0.35 & 0.50 & -0.08 & 0.03 & -0.02 & 0.34 & 0.14 & -0.06 & 0.33 & 0.33 & 1.00 & & & & & \\
\hline 12. CTR.PRS & 0.36 & 0.38 & -0.11 & -0.09 & -0.07 & 0.10 & 0.24 & 0.12 & 0.35 & 0.15 & 0.86 & 1.00 & & & & \\
\hline 13. ADM.PRS1 & 0.51 & 0.28 & 0.00 & -0.08 & -0.13 & 0.06 & 0.15 & 0.04 & 0.19 & 0.22 & 0.30 & 0.25 & 1.00 & & & \\
\hline 14. ADM.PRS2 & 0.54 & 0.34 & -0.06 & -0.03 & -0.07 & 0.39 & 0.22 & 0.05 & 0.26 & 0.27 & 0.48 & 0.43 & 0.71 & 1.00 & & \\
\hline 15. LOC.RSP & 0.01 & -0.11 & 0.23 & 0.00 & 0.13 & 0.15 & 0.13 & 0.11 & -0.24 & -0.10 & -0.11 & 0.06 & 0.05 & -0.08 & 1.00 & \\
\hline 16. QLT.RSP & 0.40 & 0.20 & 0.02 & -0.14 & -0.04 & 0.48 & 0.13 & 0.13 & 0.15 & 0.33 & 0.18 & 0.13 & 0.42 & 0.39 & 0.13 & 1.00 \\
\hline
\end{tabular}

Note: Pearson correlation is measured between variables from 1 to 6 . Polychoric correlation between variables from 7 to 16 . Polyserial method is applied in interaction cases.

to a private company or 0 if it is directly managed by the municipal administration or a public company. Distinguishing between private or public management is critical because each type of institution has different goals. A private company must sustain a profitable business (Maietta and Gorgitano, 2016; Sonnino, 2009), and the introduction of organic food is expected to guarantee the company's profit and competitiveness. Conversely, public administration may be driven by interests of social welfare and environmental protection (Grandia et al., 2015). In addition, pressure from stakeholders must also be considered. This pressure plays a critical role in influencing the choices concerning the introduction of quality food in the PSFP for both private companies and public administration (Galli et al., 2014). In fact, despite the need to control for limiting costs, both are required to meet the expectations of stakeholders. In this context, a number of binary variables were defined to assess the role of different players in encouraging the introduction of organic food within the public school system. First, we assessed the introduction of organic food by the direct initiative of catering service management (MNG.STR) in order to provide an improved service for a number of reasons concerning social responsibility and/or economic sustainability and/or reputation (Maietta and Gorgitano, 2016) independently by a contractual obligation to introduce GPP criteria, which the "rewarding" criteria of CAM invite to do. Second, administration pressure was explored by using two binary variables (where 0 was no pressure) as differently related to environmental safety (ADM.PRS1) and young people's health (ADM.PRS2) according to what consumer behavior studies suggested as the main attributes of credence to organic food by consumers (Gracia and de Magistris, 2008). Third, the presence of a Canteen Committee (CTR.BRD) and the potential pressure exerted by the Canteen Committee (CTR.PRS) as driven by families caring for their children were also considered (Galli et al., 2014; Gracia and de Magistris, 2008).

Finally, we included indicators on the perception of the importance of local food and quality food in order to understand if organic food was in line with the attention to local economy and certified regional products, as suggested by CAM and the literature (Caputo et al., 2017; Italian Ministry of Environment and the Protection of Natural Resources, 2011a; Smith et al., 2016). Local (LOC.RSP) and quality responsibility (QLT.RSP) of PSFP management are also introduced based on the consideration that the higher the PSFP's responsiveness to local/regional or PDO/PGI products, the more it is likely to be oriented to organic food procurement.
A summary of variables and descriptive statistics are given in Table 1.

\subsection{Model specifications}

This study attempts to explore the factors that affect the introduction of organic food in the PSFP. The dependent variable is computed as the number of organic product types that are introduced in the PSFP. Commonly, count variables are analyzed using the Poisson Regression model (PR). However, when the distribution is characterized by over dispersion, the Negative Binomial Regression (NBR) model is considered to be more appropriate. The difference in BIO.ADP between mean and standard deviation values (Table 1 ) typically suggests the occurrence of over dispersion and thus the potential relevance of the NBR versus the PR model. In addition, the high rate of zero counts (more than 30\%) makes the Zero-Inflated Negative Binomial (ZINB) model even more appropriate to accommodate both over-dispersion and overabundance of zero in a count data regression model. The significance of the dispersion parameter for Negative Binomial (Theta) in Table 3 confirms the hypothesis of over-dispersion. The Vuong test is regularly used to determine whether estimating a zero-inflation component is appropriate or whether a single-equation count model should be used (Desmarais and Harden, 2013). Both the AIC-corrected (Z-stat is 10.22 and p-value is 0.000 ) and the BIC-corrected (Z-stat is 8.27 and $p$ value is 0.000 ) results of the Vuong test correspond to a statistically significant selection of the ZINB model with respect to the PR and NBR models. The analysis of Log-Likehood and Aikake Information Criteria (AIC), as shown in Table 3 , further supports this contention (AIC in ZINB is lower than in other models).

Specifically, ZINB is a mixture model that generates, for each observation, two data generation processes that combine a binary distribution (that is degenerate at zero) and an ordinary count distribution (that is attributable to a negative binomial distribution because of the over dispersion). Thus, the ZINB model has the following general form:

$P(y \mid n b(y \mid, \theta))=\left\{\begin{array}{l}\lambda+(1-\lambda) \cdot n b(y \mid, \theta), y=0 \\ (1-\lambda) \cdot n b(y \mid, \theta), y>0\end{array}\right.$

where $n b(y \mid \mu, \theta)$ is the negative binomial distribution function, which depends on $\mu$ and $\theta$. The former is the mean value of the NB distribution. The latter is the over dispersion parameter (theta), which is 
Table 3

Regression models.

\begin{tabular}{|c|c|c|c|c|}
\hline & \multirow[t]{2}{*}{ PR model } & \multirow[t]{2}{*}{ NBR model } & \multicolumn{2}{|l|}{ ZINB model } \\
\hline & & & LR & NBR \\
\hline Intercept & $0.483(0.103)^{\ldots * k}$ & $-0.023(0.239)$ & $2.286(0.706)^{* * *}$ & $1.447(0.209)^{*+2.2 k}$ \\
\hline \multicolumn{5}{|c|}{ Territorial variables } \\
\hline POP.DEN & $0.353(0.021)^{* * * k / k}$ & $0.482(0.067)^{\text {k*k*k}}$ & $-0.822(0.266)^{k \times k}$ & $0.213(0.053)^{3+x+k}$ \\
\hline SZE.PSS & $0.0121(0.021)$ & $-0.012(0.058)$ & $-1.895(1.242)$ & $-0.018(0.045)$ \\
\hline FRM.DEN & 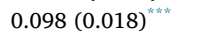 & $0.201(0.058)^{k+k x}$ & $0.072(0.175)$ & 0.095 (0.053). \\
\hline SZE.FRM & $0.105(0.017)^{* * * *}$ & $0.171(0.057)^{* * * k}$ & $-0.397(0.178)^{*}$ & $0.035(0.046)$ \\
\hline BIO.CAP & $-0.148(0.036)^{3.12}$ & $-0.139(0.073)$ & $0.201(0.164)$ & $-0.081(0.129)$ \\
\hline \multicolumn{5}{|c|}{ Market constraints } \\
\hline MKT.SPP & $-0.191(0.041)^{*+k x}$ & $-0.351(0.143)^{k}$ & $0.556(0.465)$ & $-0.149(0.103)$ \\
\hline MKT.CST & $-0.192(0.031)^{3.1 * k}$ & -0.179 (0.107) & $0.191(0.367)$ & $-0.174(0.077)^{*}$ \\
\hline \multicolumn{5}{|c|}{ PSFP Management and governance } \\
\hline MNG.PRV & $0.874(0.099)^{k \text { k.k.k }}$ & $0.877(0.221)^{* k \times k}$ & $-0.527(0.596)$ & $0.742(0.188)^{\text {*.t.ke }}$ \\
\hline MNG.STR & $0.462(0.032)^{* * * k}$ & $0.838(0.109)^{\text {**k*k}}$ & $-3.793(0.553)^{1.3 * x}$ & $0.106(0.081)$ \\
\hline CTR.PRS & $0.332(0.041)^{* k+k}$ & $0.612(0.173)^{* * * *}$ & $-3746(1.253)^{k+k}$ & $0.253(0.111)^{*}$ \\
\hline ADM.PRS1 & $0.658(0.032)^{* * * k}$ & $0.934(0.112)^{* \ldots * k}$ & $-4.938(0.911)^{t * k * k}$ & $0.324(0.079)^{*}$ \\
\hline \multicolumn{5}{|c|}{ Concern for local and certified origin production } \\
\hline LOC.RSP & $0.032(0.031)$ & $-0.081(0.107)$ & $-0.743(0.373)^{*}$ & $-0.744(0.077)$ \\
\hline QLT.RSP & $0.398(0.037)^{* * * *}$ & $0.692(0.115)^{k+* x \cdot k}$ & $-1.896(0.384)^{* * * *}$ & $0.208(0.087)^{*}$ \\
\hline N.obs & 524 & 524 & 524 & \\
\hline Theta (log) & - & $0.863(0.073)^{3 * * * *}$ & $0.888(0.097)^{3 * * *}$ & \\
\hline$D f$ & 14 & 15 & 29 & \\
\hline Log-Likelihood & -2455.03 & -1490.74 & -1320 & \\
\hline AIC & 4938.1 & 3011.47 & 2698.7 & \\
\hline VIF mean & 1.172 & 1.172 & - & \\
\hline VIF max & 1.614 & 1.614 & - & \\
\hline
\end{tabular}

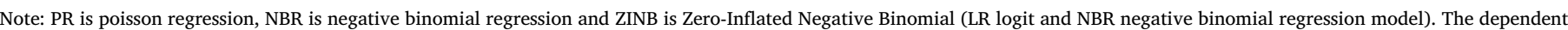
variable is the adoption of organic food (BIO.ADP). Standard errors are in brackets. Standardized coefficients are shown for numeric variables.

* Significant levels are $\mathrm{p}<0.05$.

** Significant levels are $\mathrm{p}<0.01$

$* * *$ Significant levels are $\mathrm{p}<0.001$

determined by the variance of the NB distribution $\mu(1+\theta \mu)$. The $\lambda$ is the probability of being an excess zero, and it is typically modelled with a logit link. In other words, the logit regression (LR in Table 3) of the ZINB model explores the factors that prevent the adoption of organic products in PSFP (the probability $\mathrm{y}=0$ ), while the negative binomial regression (NBR in Table 3 ) measures the factors that affect the adoption intensity of organic products in PSFP across municipalities.

\section{Results}

Table 1 highlights the descriptive statistics of explored variables. Table 2 shows a mixed correlation matrix that consists of Pearson product-moment correlations between numeric variables, polyserial correlations between numeric and logical/factor variables and polychoric correlations between logical/factor variables (hector function in polycor package of R software 3.2.3). Analysis of correlation is realized to control for collinearity across exploratory variables. The data highlights two critical correlations. The first strong correlation $(r=.86$ in Table 3) is between the presence of a Canteen Committee (CTR.BRD) and the pressure the Canteen exerts (CTR.PRS); the latter is adopted in spite of CTR.BRD in order to reduce collinearity risk. The second strong correlation ( $r=.71$ in Table 2 ) is between ADM.PRS1 and ADM.PRS2. Similarly, only ADM.PRS1 is introduced in regression models. No other correlation results were higher than 0.5. The Value Inflation Factor (VIF) test is further applied on both the PR and NBR models. Values lower than 2 suggest no serious collinearity risk.

Table 3 shows the results of the PR, NBR and ZINB models. Because it is considered the best model, only the results of the ZINB model are described.
The first process of the ZINB model implements the logit $(\lambda)$ as the dependent variable, where $\lambda$ is the likelihood that zero will be the result. This means the coefficient must be conversely interpreted if you are exploring the chance to introduce organic food in public catering procurement. The second process is based on $\log (\gamma)$, where $\gamma$ is the integer number of product types introducing organic food, and is used to assess the intensity of such an adoption.

The logit model (LR in Table 3 ) highlights that the chance to introduce organic food in PSFP is higher for the municipalities with higher urbanization level (POP.DEN) and larger local farms (SZE.FRM). Moreover, the probability of initial adoption increases when the adoption is proposed by the catering service management (MNG.STR). Pressure from the Canteen Committee (CRT.PRS) and the municipal administration (ADM.PRS1) also play a critical role in the adoption of organic food. Finally, the initial introduction of organic food further depends on the attention to local and quality food (LOC.RSP and QLT.RSP). The initial introduction of organic food seems not to be affected by the cost (MKT.CST) or the availability (MKT.SPP) of organic food, as there is no significant connection to other territorial variables such as the presence of organic production in the area (BIO.CAP).

The negative binomial model (NBR) measures the extent to which the public catering is inclined to provide organic food in the school system. The data shows that the urbanization level (POP.DEN) affects both the introduction and the intensity level of the adoption of organic food. Moreover, the adoption level significantly increases for PSFP managed by private organizations more than by public organizations (MNG.PRV). However, even though the private catering business strategy is a critical driver of the decision to introduce organic food, it is insignificant to adoption intensity. This is because of the negative 
relevance of high market costs (MKT.CST) for organic rather than conventional food. If the introduction may be useful to increase market reputation, an excessive adoption is expected to reduce the benefit-cost ratio. No effect is related to market availability (MKT.SPP) and to local capacity for organic agriculture production (BIO.CAP).

Strong pressure from administrations and the Canteen Committee regarding ensuring health and environmental substantiality leads management to adopt more organic food, but administration pressure is more significant. This confirms the critical role played by stakeholders in PSFP, especially in a context in which the relevance of and stress for safety and health are continuously growing because of European pressure. Finally, the increasing adoption of organic food is connected to the introduction of GPI and DPO but not to the attention to local provision (LOC.RSP).

\section{Discussion and policy remarks}

Considering the relevance that municipalities have in implementing sustainable procurement (Morgan and Sonnino, 2007; Risku-Norja and Løes, 2016; Testa et al., 2016), this study determined which factors affect the initial introduction and the intensity of adoption of organic food in PSFP at the municipal level. So far, the factors that explain the purchase of organic food have been analyzed for consumers (i.e. Gracia and Magistris, 2008; Torjusen et al., 2004; Agovino et al., 2017), but not for complex systems such as PSFP, in which several actors contribute to defining purchasing strategies and in which different sustainability options need to be taken into account (Wahlen et al., 2012; Mikkelsen and Sylvest, 2012; Risku-Norja and Løes, 2016; Maietta and Gorgintano, 2016). This study has provided a systematic analysis of the factors to foster sustainability, and further analysis could include other indicators that consider the specific context of the case study or other relevant issues. Moreover, this study has worked at the regional level to provide an intermediary framework of analysis, which is useful for national plans to better drive guidelines and drivers, while most of the studies until now have been especially based on case study analysis (i.e. Sonnino, 2009; Risku-Norja and Løes, 2016; Wahlen et al., 2012). Moreover, this study focused not only on the introduction of organic food but also on the diversification and intensification of the organic food procurement, which our study demonstrates is significantly important even if it is not considered in the regulation.

The first finding suggests that urbanized areas are more prone to introduce organic food and to intensify the provision. This is consistent with the literature on consumer behavior that indicates the higher propensity to buy organic food for urban dwellers (Radman, 2005; Torjusen et al., 2004). According to Torjusen et al. (2004), the physical distance between urban consumers and producers results in a lack of personal trust between the food demanders and food producers, thus leading urban consumers to buy more trustable food, such as certified organic food.

In our analysis, the price is not a market constraint in including organic food, but it becomes a limit for increasing its volumes. The rewarding criteria thus act only partially in overcoming the strict cost effectiveness criteria. On the other hand, the possibility of increasing the provision of organic foods is greater when the procurement is directly managed by private companies. This is probably because private companies are usually big catering companies, and when they have to introduce organic food they rely on large volumes of product at once (Sonnino, 2009; Risku-Norja and Løes, 2016; Lehtinen, 2012). In fact, large volumes enable a more efficient organization of the supply, thus reducing the costs of organizing the food chain. Eventually, this organization can possibly overcome the cost constraints connected to the increase in organic food's distribution.

The first adoption of organic food is more likely to happen when municipalities are concerned also with local supply basin and with certified food quality such as PGI and PDO. Nevertheless, a more adoption of organic food is detected when catering services pay attention to certified quality products such as PDO/PGI, but not to local supply's products. While the most important PGI and PDO can count on a structured and organized supply system and on huge amounts of standardized products that fit the PSFP's needs, the local supply is mostly based on fragmented and individualized activities. Until now, the local supply does not meet the public-private procurement requirements in terms of quality, availability and cost-effectiveness (Lehtinen, 2012; Thompson et al., 2014; Risku-Norja and Løes, 2016), but the local supply can more easily be valorised in direct relations with consumers (Filippini et al., 2016). The increasing inclusion of local supply may also be hampered by the difficulty of local public managers to interpret the European regulation on free competition (Morgan, 2008). Nevertheless, several researches have indicated ways to overcome such stakes, such as the introduction of seasonal products, the contract division into lots, in order to encourage local producers and discourage big international companies (Nölting, 2009; Stein, 2013; Maietta and Gorgitano, 2016).

The role of the actors and their pressure is fundamental and peculiar.

In the case of catering companies their business strategy acts positively for the initial adoption of organic food, but it is no longer significant in differentiating the offer of organic products. In other words, to build a market reputation (Maietta and Gorgitano, 2016) or to respond to the CAM's rewarding criteria, catering companies are willing to adopt organic food, perhaps only in specific and more reachable food categories, but such motivations are no longer a driver in differentiating the offer. This is probably due to the persisting price premium and the resulting competition in the organic food market. Despite the growth of the EU organic production (Eurostat, 2016), price premium occurs as the market growth registered in Europe (IFOAM, 2016) is especially demand pulled: in Europe, there is a per capita spending of EUR 43 with an increasing trend (IFOAM, 2016). Catering companies participating to public procurement encounter both cost and logistic constraints in differentiating products categories, due to the need to buying and distributing large volumes of product respecting tenders' rules and timing (Sonnino, 2009). Other food chains based on individual consumers choices still seem more competitive in absorbing the demand of organic products, as specialised retailers and supermarkets (IFOAM, 2016; EP, 2015).

On the contrary, the pressure of Canteen Committees in having organic food favours both the inclusion and the diversification of organic food, thus confirming the important role of parents (Clelland et al., 2013), already analyzed in qualitative analysis of Italian case studies (i.e. Galli et al., 2014; Sonnino, 2009). In Italy, despite the high percentage of schools that organize food education actions (74\%), only 1 school up to 3 includes the parents in such activities (Italian Ministry of Health, 2014). Food education actions are thus recommended not only to pupils, but also to families to understand and accept the rise of costs (Morgan and Sonnino, 2008), as well as to teachers to empower the canteen users toward more sustainable diets (Wahlen et al., 2012; Otzuki, 2011).

This study also confirms the important role of public bodies' belief and motivations in striving towards sustainable procurement (Grandia et al., 2015; Testa et al., 2016). Children's health and environmental sustainability are in fact both relevant leverages for public bodies and play a crucial role both in introducing and diversify organic food 
inclusion. The role of public bodies is fundamental because they must mediate the catering companies' constraints in terms of market availability, competitiveness and logistics, and the family interests and needs, such as the request for good quality food at the lowest price possible. In this context, they operate with sustainability objectives typical of public bodies: in fact, by definition a publicly-funded institution should play a determinant role in addressing sustainability issues, as public bodies should promote the "public good" (Cerutti et al., 2016; Sonnino, 2009). Considering the specific public function of PSFP, to improve the sustainability assessment of public tenders, we recommend the inclusion of specific tools (Smith et al., 2015), as the Food Chain Evaluator (Caputo et al., 2017), the analysis of Social Return On Investment (Jones et al., 2016), and others (i.e. Goggins and Rau, 2016; Cerutti et al., 2016) in the evaluation process of public tenders. These tools should guarantee a greater understanding of the different aspects and options of sustainability according to the different actors involved: healthy diets, economic profitability, social inclusion, environmental impact. At the same time, these tools should improve the visibility and acquaintance of the sustainability's options connected to organic food for the actors involved in the PSFP.

We finally suggest that the territorial alliance between families, private companies and committed local public bodies can sustain the increased provision of organic food as well as the inclusion of local supply. In the recent Italian research project "Bioregione" ${ }^{3}$ (Porro et al., 2014), "territorial laboratories" were organized in different areas of Lombardy region to evaluate the integration of the different sustainability options along the PSFP food chain, and the possible territorial organization of the demand and offer to foster the sustainability in PSFP. Beyond the public bodies, the Canteen Committees and the catering companies, researchers included also farmers, food distributors, local consumers associations. The creation of this territorial network had also the purpose of firstly reasoning about the possibility to pursue the "capitolato condiviso" ("shared purchasing contract") by which the different stakeholders provide their points of view in the definition of the public purchasing contracts. Instead of simply imposing criteria by the municipality upon contractors, public bodies can better foster sus- tainability through the creation of these territorial networks (De Schutter, 2014).

\section{Concluding remarks}

To conclude, the determinants of the adoption of the green alternative show some barriers and constraints determined by the territorial context, the market and the regulation. On the other side, the increasing demand for sustainable, healthy and quality food can be the leverage for the growth of an integrated and participated food system in which the PSFP is the hub for the local development, the strengthening of small and medium enterprises and the lab for developing new knowledge and awareness of food. The issue seems especially relevant now that the GPP criteria "Food Procurement and Catering services" are currently in revision (Boyano et al., 2017) to improve the GPP implementation, which does not currently meet the set target (Renda et al., 2012). In our opinion, in order to increase the quota of organic food and improve the sustainability of PSFP, specific policies should be focused in: promoting food education actions addressed to families, pupils, teachers, public managers about the different sustainability's options in PSFP; creating opportunities for territorial networks in order to include the points of view of local stakeholders as farmers, distributors, researchers in the purchasing contracting; developing and including tools which may evaluate at the same time the different aspects of the sustainability in the tender process. These actions should be considered at local, regional, national and European level in accordance with subsidiarity principle. A deeper knowledge and awareness of the organic food procurement system dynamic and the actors' role and social interactions are fundamental to address more targeted and efficient policies.

\section{Funding}

This work was supported by Cariplo Foundation in the framework of the project BIoregione

\section{Appendix A. Appendix}

Below is reported the survey about public school food procurement dispensed to municipalities of Lombardy. Data concerning territorial characteristics of interviewed municipalities are provided by ISTAT.

1. What is the approximate number of monthly administered meals?

2. The public school food procurement is mainly managed by:

- municipal administration

- public company

- private company

3. Are Canteen Committees officially organized in the schools of municipality? (Yes/No)

4. The introduction of organic products in the public-school food procurement was encouraged by:

- municipal administration for reasons related to environmental safety (Yes/No/Don't know)

- municipal administration for reasons related to young people's health (Yes/No/Don't know)

- private company which food procurement is subcontracted to (Yes/No/Don't know)

- families and/or Canteen Committee (Yes/No/Don't know)

5. Which are the main constraints in order to introduce organic products in the public-school food procurement:

- the low availability of organic products on the market

- the higher costs of organic as compared to conventional products

- difficulty due to transport ${ }^{4}$

- difficulty due to storage ${ }^{4}$

- difficulty due to identify providers ${ }^{4}$

- other

\footnotetext{
${ }^{3}$ http://www.bioregione.eu/index.htm.

${ }^{4}$ These criticality is not considered to be implemented in the modelling because the number of responses was insignificant.
} 
6. Complete the following table, focusing on the main tendency.

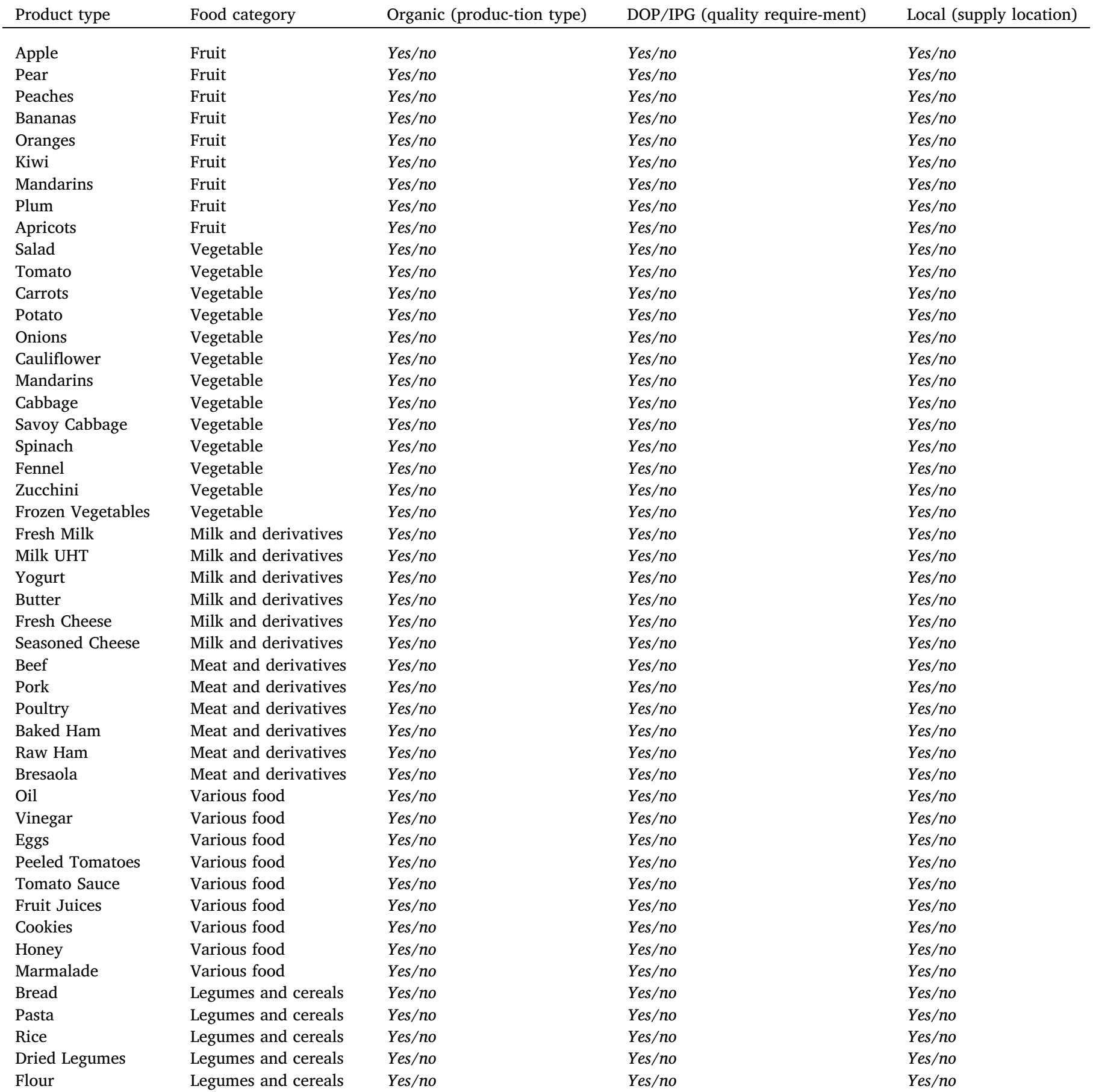

\section{References}

Bio Bank, 2017. Rapporto Bio Bank 2017. Analisi e statistiche del biologico in Italia secondo i censimenti Bio Bank dall'alimentazione alla cosmesi. https://issuu.com/ biobank/docs/rapporto_bio_bank_2017 (Accessed 20.09.2017).

Bergström, K., Solér, C., Shanahan, H., 2005. Professional food purchasers' practice in using environmental information. Brit. Food. J. 107 (5), 306-319.

Bocchi, S., Spigarolo, R., Sarti, V., Nölting, B., 2009. Organising supply chains of organic products for Italian school meals-The case of the province and of the city of Piacenza. In Providing organic school food for youths in Europe-Policy strategies, certification and supply chain management in Denmark, Finland, Italy and Norway. Proceedings of the iPOPY seminar held at the BioFach February 20th 2009 in Nuremberg, Germany (pp. 23-29). International Centre for Research in Organic Food Systems (ICROFS).
Boyano, A., Espinosa, Quintero, R., 2017. Revision of the EU GPP criteria for Food procurement and Catering services (JRC). http://susproc.jrc.ec.europa.eu/Food_ Catering/docs/170127_EU\%20GPP\%20Food\%20catering\%20criteria_TR2.0.pdf (Accessed 06/10/2017).

Brantsæter, A.L., Ydersbond, T.A., Hoppin, J.A., Haugen, M., Meltzer, H.M., 2017. Organic food in the diet: exposure and health implications. Annu. Rev. Public Health 38, 295-313.

Brunori, G., Galli, F., Barjolle, D., Van Broekhuizen, R., Colombo, L., Giampietro, M., Kirwan, J., Lang, T., Mathijs, E., Maye, D., de Roest, K., Rougoor, C., Schwarz, J., Schmitt, E., Smith, J., Stojanovic, Z., Tisenkopfs, T., Touzard, J.-M., 2016. Are local food chains more sustainable than global food chains? considerations for assessment. Sustainability 8 (5), 449.

Caputo, P., Clementi, M., Ducoli, C., Corsi, S., Scudo, G., 2017. Food Chain Evaluator, a tool for analyzing the impacts and designing scenarios for the institutional catering in Lombardy (Italy). J. Cleaner Prod. 140, 1014-1026. 
Cerutti, A.K., Contu, S., Ardente, F., Donno, D., Beccaro, G.L., 2016. Carbon footprint in green public procurement: Policy evaluation from a case study in the food sector. Food Policy 58, 82-93.

Chamber of Commerce, 2014. Facility management. Il mercato pubblico dei servizi. Manuale operativo. di ristorazione. http://www.rm.camcom.it/moduli/ downloadFile.php? file = oggetto pubblicazioni/1530911473600 OManuale \%20Facility\%20Management\%20Ristorazione.pdf (Accessed 16/05/2017).

Clelland, T., Cushman, P., Hawkins, J., 2013. Challenges of parental involvement within a health promoting school framework in New Zealand. Educ. Res. Int. http://dx.doi. org/10.1155/2013/131636.

De Schutter, O., 2014. The Power of Procurement Public Purchasing in the Service of Realizing the Right to Food. United Nations Human Rights Council (Accessed 06.03.2016).

Desmarais, B.A., Harden, J.J., 2013. Testing for zero inflation in count models: Bias correction for the Vuong test. Stata J. 13 (4), 810-835.

Ecosistemi, 2012. Indagine ristorazione collettiva 2012. accessed 10.10.2017. http:// www.minambiente.it/sites/default/files/archivio/allegati/GPP/rapporto_indagine_ ristorazione_2012.pdf.

Eurostat, 2016. Organic farming statistics. accessed 1/2/2018. http://ec.europa.eu/ eurostat/statistics-explained/index.php/Organic farming statistics.

Commission, European, 2008. EU GPP criteria - Catering \& Food - Green Public procurement (GPP) Product Sheet. accessed 07.10.2106. http://ec.europa.eu/ environment/gpp/eu_gpp_criteria_en.htm.

Commission, European, 2015. Study on "Strategic use of public procurement in promoting green, social and innovation policies" Final Report. accessed 11.10.2016. http://ec.europa.eu/DocsRoom/documents/17261/attachments/1/translations/en/ renditions/native.

European Commission, 2016a. Public Procurement Indicators 2015. http://ec.europa.eu/ DocsRoom/documents/20679 (Accessed 11.10.2016).

European Commission, 2016b. Buying green! A handbook on green public procurement. http://ec.europa.eu/environment/gpp/pdf/Buying-Green-Handbook-3rd-Edition.pdf (Accessed 23.9.2016)

European Parliament, 2015. Organic food: Helping EU consumers make an informed choice. http://www.europarl.europa.eu/RegData/etudes/BRIE/2015/557009/EPRS BRI(2015)557009_EN.pdf (Accessed 1/2/2018)

Galli, F., Brunori, G., 2012. Verso una ristorazione scolastica italiana più sostenibile: sustainable public procurement. Agriregionieuropa 29, 71-81.

Galli, F., Brunori, G., Di Iacovo, F., Innocenti, S., 2014. Co-producing sustainability: in volving parents and civil society in the governance of school meal services. a case study from Pisa, Italy. Sustainability 6, 1643-1666.

Goggins, G., Rau, H., 2016. Beyond calorie counting: assessing the sustainability of food provided for public consumption. J. Cleaner Prod. 112, 257-266.

Gracia, A., de Magistris, T., 2008. The demand for organic foods in the South of Italy: A discrete choice model. Food Policy 33, 386-396.

Grandia, J., Steijn, B., Kuipers, B., 2015. It is not easy being green: increasing sustainable public procurement behaviour. Innovation: Eur. J. Social Sci. Res. 28, 243-260.

Grossi, E., Sacco, P.L., Blessi, G.T., Cerutti, R., 2011. The impact of culture on the individual subjective well-being of the Italian population: an exploratory study. Appl. Res. Quality Life 6 (4), 387-410.

IFOAM, 2016. Organic in Europe. Prospects and developments 2016. http://www.ifoameu.org/sites/default/files/ifoameu_organic in europe 2016.pdf

ISTAT, 2012. La scuola e le attività educative. accessed 13.12.2017. https://www.istat. it/it/files/2012/10/report-scuola-2011.pdf?title $=\mathrm{La}+$ scuola + e + le + attivit $\%$ C3\%A0 + educative +- + 03\%2Fott $\% 2$ F2012 + - + Testo + integrale.pdf.

Italian Ministry of Health, 2010. Linee di indirizzo nazionale per la ristorazione scolastica. accessed 25.09.2016. http://www.salute.gov.it/imgs/c_17_pubblicazioni_1248 allegato.pdf.

Italian Ministry of Health, 2014. Okkio alla Salute: Sintesi dei risultati 2014. accessed 19.10.2016. www.epicentro.iss.it/okkioallasalute/pdf2015/SINTESI_16gen.pdf.

Italian Ministry of Environment and the Protection of Natural Resources, 2008. Action Plan for the environmental sustainability of consumption in the public administration sector - GPP NAP. accessed 06.10.2017. http://www.minambiente.it/sites/default/ files/archivio/allegati/GPP/all.to_21_PAN_GPP_definitivo_EN.pdf.

Italian Ministry of Environment and the Protection of Natural Resources, 2011a. Criteri ambientali minimi per il servizio di ristorazione collettiva e la fornitura di derrate alimentari. accessed 06.10.2017. http://www.minambiente.it/sites/default/files/ archivio/allegati/GPP/all.to_40_CAM_ristorazione_collettiva_e_derrate_alimentari_25 07.2011.pdf.

Italian Ministry of Environment and the Protection of Natural Resources, 2011b. Relazione di accompagnamento (background document) relativa ai "Criteri ambientali minimi" della categoria "Ristorazione" (servizio mense e forniture alimentari). accessed 06.10.2017. http://www.minambiente.it/sites/default/files/ archivio/allegati/GPP/cam relazione accompagnamento ristorazione.pdf.

Izumi, B.T., Wright, D.W., Hamm, M.W., 2010. Farm to school programs: exploring the role of regionally-based food distributors in alternative agrifood networks. Agric Hum. Values 27, 335-350.

Jones, M., Pitt, H., Oxford, L., Orme, J., Gray, S., Salmon, D., Means, R., Weitkamp, E.,
Kimberlee, R., Powell, J. 2016. Food for life: A social return on investment analysis of the locally commissioned programme. Full Report. Project Report. UWE, Bristol. http://eprints.uwe.ac.uk/31897/1/12_Jones_et_al_(2016)_Food_for_Life_LCs_SROI Full\%20Report_v05.pdf (Accessed 13.1.2018)

Kneafsey, M., Eyden-Wood, T., Bos, E., Sutton, G., Santini, F., y Paloma, S.G., Venn, L., Schmutz, U., Balázs, B., Trenchard, L., 2013. Short Food Supply Chains and Local Food Systems in the EU: a state of play of their socio-economic characteristics. Eds. European Commission, Joint Research Centre, Institute for Prospective Technological Studies. Sevilla, Spain. pp 128. http://agrilife.jrc.ec.europa.eu/documents/ SFSChainFinaleditedreport_001.pdf.

Lehtinen, U., 2012. Sustainability and local food procurement: a case study of Finnish public catering. Br. Food J. 114, 1053-1071.

Løes, A., Nölting, B., 2011. Increasing organic consumption through school meals-lessons learned in the iPOPY project. Org. Agric. 1 (2), 91-110.

Maietta, O.W., Gorgitano, M.T., 2016. School meals and pupil satisfaction. Evidence from Italian primary schools. Food Policy 62, 41-55.

Mikkelsen, B.E., Sylvest, J., 2012. Organic foods on the public plate: technical challenge or organizational change? J. Foodservice Business Res. 15, 64-83.

Morgan, K., 2008. Greening the realm: sustainable food chains and the public plate. Regional Stud. 42, 1237-1250.

Morgan, K., Sonnino, R., 2007. Empowering consumers: the creative procurement of school meals in Italy and the UK. Int. J. Consumer Stud. 31, 1-7.

Morgan, K., Sonnino, R., 2008. The School Food Revolution: Public Food and the Challenge of Sustainable Development. Earthscan, London; Sterling, VA.

Neto, B., Rodríguez Quintero, R., Wolf, O., Sjögren, P., Lee, P., 2016. Revision of the EU Green Public Procurement Criteria for Food and Catering Services - Technical report for the 1st AHWG meeting - JRC Technical Report (Sevilla, Spain: Joint Research Group - Institute for Prospective Technological Studies). http://susproc.jrc.ec.europa. eu/Food_Catering/docs/EU\%20GPP\%20Food\%20Catering\%20services_Technical \%20Report.pdf (Accessed 10.10.2017).

New, S., Green, K., Morton, B., 2002. An analysis of private versus public sector responses to the environmental challenges of the supply chain. J. Public Procurement 2 93-105.

Nölting, B., 2009. Providing organic school food for youths in Europe-Policy strategies, certification and supply chain management in Denmark, Finland, Italy and Norway. International Centre for Research in Organic Food Systems (ICROFS). CORE Organic Series Report. Proceedings of BioFach 2009, GastroForum, Nuremberg, Germany, February 20th 2009.

Nuutila, J., Kurppa, S., 2017. Two main challenges that prevent the development of an organic food chain at local and national level—an exploratory study in Finland. Org. Agric. 7 (4), 379-394.

Otzuki, K., 2011. Sustainable partnerships for a green economy: A case study of public procurement for home-grown school feeding. Nat. Resour. Forum 35 (2011), 213-222.

Porro, A., Corsi, S., Scudo, G., Spigarolo, G., 2014. Il contributo della ricerca Progetto Bioregione allo sviluppo di sistemi agroalimentari locali sostenibili. Scienze del Territorio 2 (2014), 311-318.

Radman, M., 2005. Consumer consumption and perception of organic products in Croatia. Br. Food J. 107, 263-273.

Renda, A., Pelkmans, J., Egenhofer, C., Schrefler, L., Luchetta, G., Selçuki, C., Ballesteros, J., Zirnhelt, A.-C., 2012. The uptake of green public procurement in the EU27. Annexes. Centre for European Policy Studies, College of Europe (Accessed 20.09.2017).

Rimmington, M., Carlton Smith, J., Hawkins, R., 2006. Corporate social responsibility and sustainable food procurement. Br. Food J. 108 (10), 824-837.

Risku-Norja, H., Løes, A.-K., 2016. Organic food in food policy and in public catering: lessons learned from Finland. Org. Agric. 1-14.

Smith, J., Andersson, G., Gourlay, R., Karner, S., Mikkelsen, B.E., Sonnino, R., Barling, D., 2016. Balancing competing policy demands: the case of sustainable public sector food procurement. J. Cleaner Prod. 112, 249-256.

Sonnino, R., 2009. Quality food, public procurement, and sustainable development: the school meal revolution in Rome. Environ. Planning A 41, 425-440.

Stein, M., 2013. Public sector food procurement in UK local authorities: ethics and sustainability. In: Röcklinsberg, H., Sandin, P. (Eds.), The Ethics of Consumption. Wageningen Academic Publishers, Wageningen.

Torjusen, H., Sangstad, L., O’Doherty Jensen, K., Kjærnes, U., 2004. European Consumers' Conceptions of Organic Food: A Review of Available Research (Oslo (SIFO), Norway: National Institute for Consumer's Research). http://orgprints.org/2490/1/ haccprapport.pdf (Accessed 13.09.2017).

Testa, F., Annunziata, E., Iraldo, F., Frey, M., 2016. Drawbacks and opportunities of green public procurement: an effective tool for sustainable production. J. Cleaner Prod. 1-8.

Thompson, O., Twomeyb, M.P., Hemphilla, M.A., Keeneb, K., Seibertc, N., Harrisonde, D.J., Stewartbf, K.B., 2014. Farm to school program participation: an emerging market for small or limited- resource farmers? J. Hunger Environ. Nutr. 9 (1), 33-47.

Wahlen, S., Heiskanen, E., Aalto, K., 2012. Endorsing sustainable food consumption: prospects for public catering. J. Consum. Policy 35, 7-21. 